\title{
Synthesis and Properties of Bio-based Non-isocyanate Thermoplastic Polyoxamide-ureas
}

Yuqi Fu, Kuan Liang, Jingbo Zhao*, Zhiyuan Zhang, and Junying Zhang*

Key Laboratory of Carbon Fiber and Functional Polymers (Beijing University of Chemical Technology), Ministry of Education; College of Materials Science and Engineering, Beijing University of Chemical Technology, Beijing 100029, China

Characterization. SEC: Samples $(25-50 \mathrm{mg})$ were dissolved in $5 \mathrm{~mL}$ DMF and were measured on an Agilent-2600 system (Agilent Technologies, Inc., USA) provided with a PLge $15 \mu \mathrm{m} 1000 \AA$ column and a refractive index detector at $25^{\circ} \mathrm{C}$. $500 \mathrm{~mL}$ DMF comprising $5 \mathrm{mM} \mathrm{LiBr}$ was used as eluent at a flow velocity of $1 \mathrm{~mL}$ $\min ^{-1}$, and polystyrene was adopted as standard samples.

FT-IR spectra were gained from a NICOLET 60SXB FTIR spectrometer (Nicolet Analytical Instruments, USA).

NMR. Samples (5-10 mg) were dissolved in DMSO-d6 and were measured on a Bruker 400 AVANCE (Bruker, USA). Tetramethylsilane was used as internal standard.

WAXS. Lamellate samples were measured on a Rigaku D/Max 2500 VB2+/PC diffractometer equipped with $\mathrm{Cu} K \alpha$ radiation to acquire wide-angle X-ray scattering patterns.

DSC. Samples (5-10 mg) were measured by a TGA Q50 analyzer (TA Instruments, USA) to obtain the second heating DSC curves $\left(10^{\circ} \mathrm{C} \mathrm{min}^{-1}\right)$, and the measurements were carried out under $\mathrm{N}_{2}$ atmosphere.

TGA testing was conducted on a TGA Q500 analyzer (TA Instruments, USA) by heating from $25^{\circ} \mathrm{C}$ to $600{ }^{\circ} \mathrm{C}$ at a rate of $10{ }^{\circ} \mathrm{C} \mathrm{min}-1$ in $\mathrm{N}_{2}$.

The method of preparing samples was similar to the one reported in the literature. ${ }^{1}$ Dumbbell-shaped bars $(50 \mathrm{~mm} \times 4 \mathrm{~mm} \times 1 \mathrm{~mm})$ were measured by a LLOYD LR30K tensile testing machine (Lloyd Materials Testing, UK) at a crosshead 
velocity of $5 \mathrm{~mm} \mathrm{~min}^{-1}$ at room temperature.

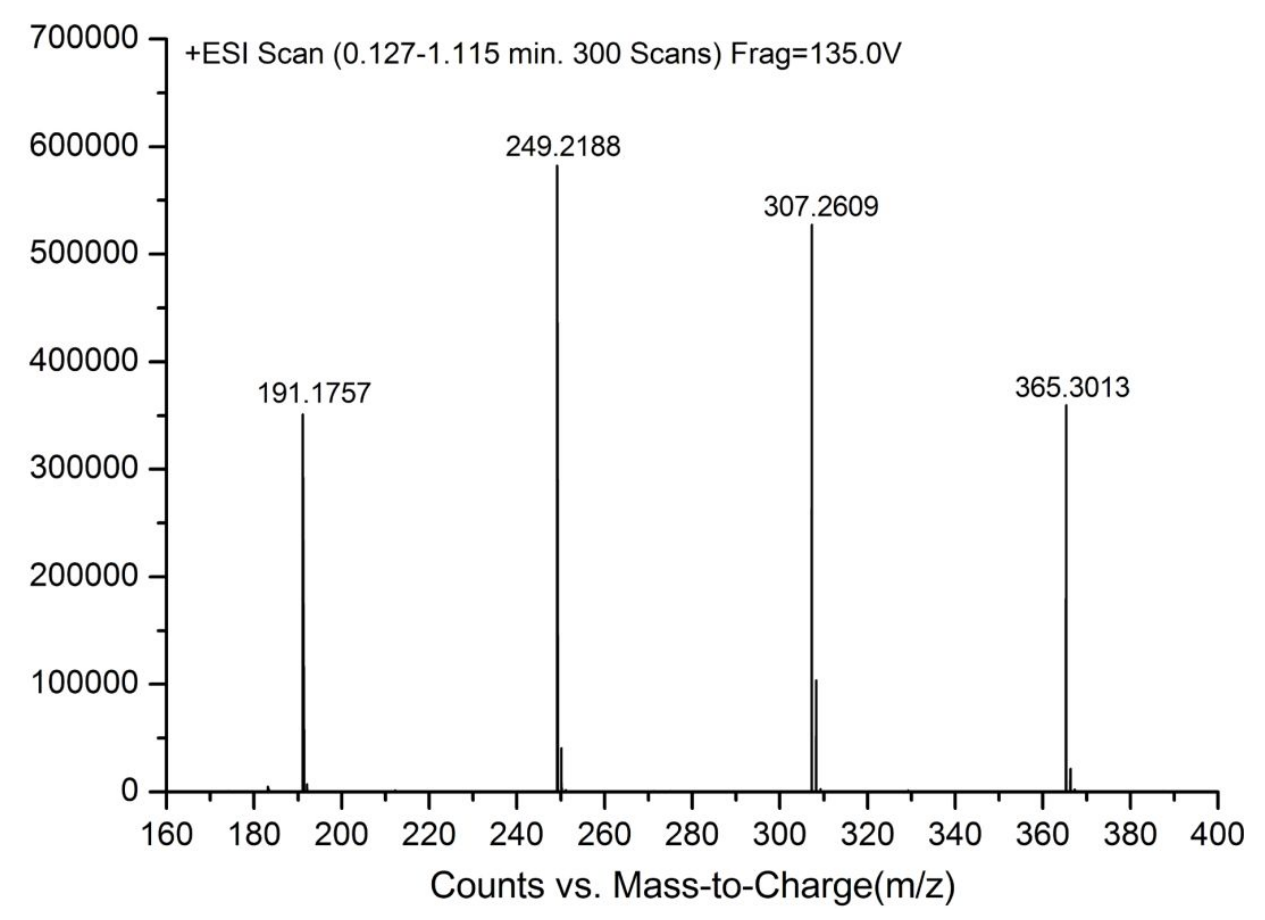

Figure S1. ESI-MS spectrum of original D230.

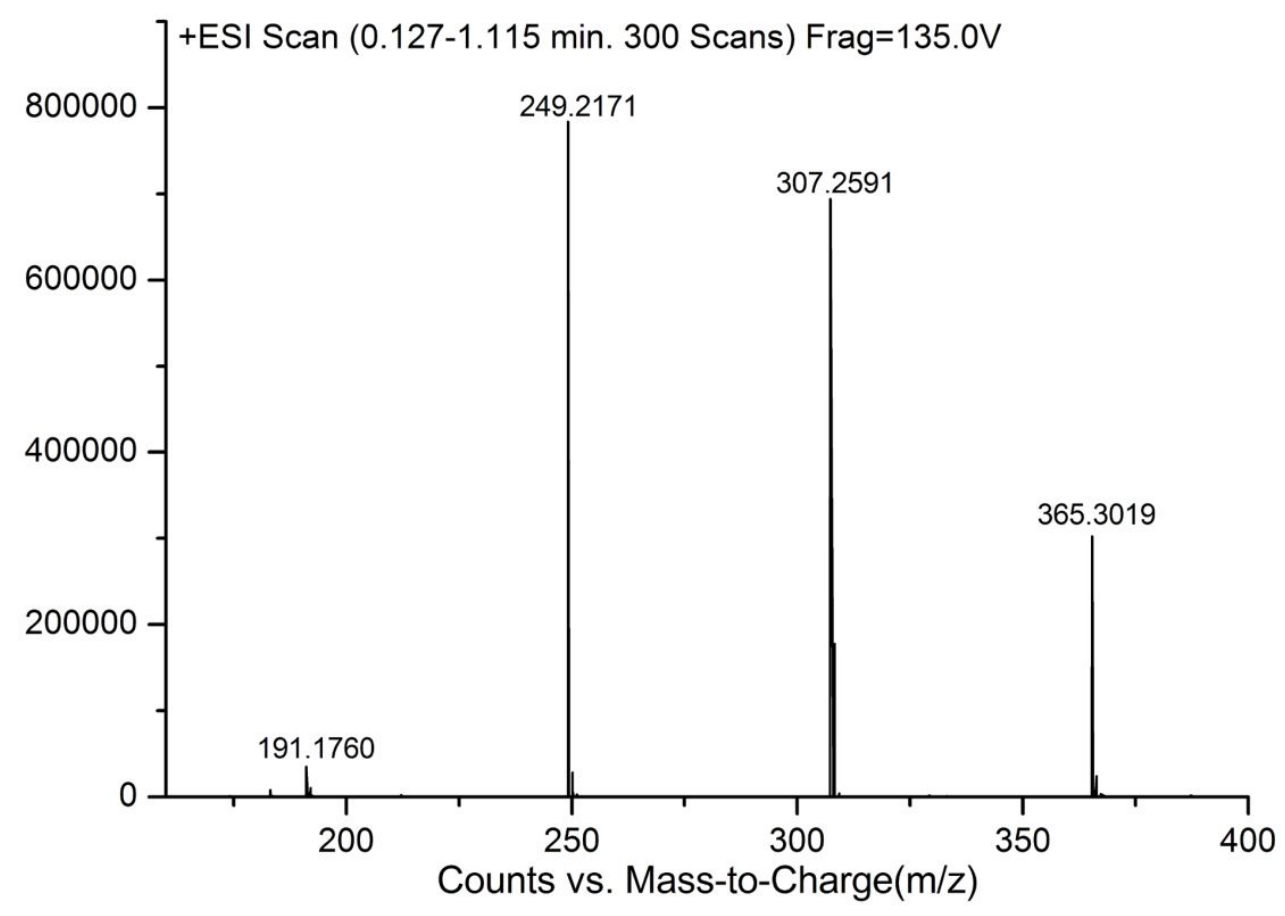

Figure S2. ESI-MS spectrum of D230 at $170{ }^{\circ} \mathrm{C}$ for $0.5 \mathrm{~h}$ under $30 \mathrm{mmHg}$. 


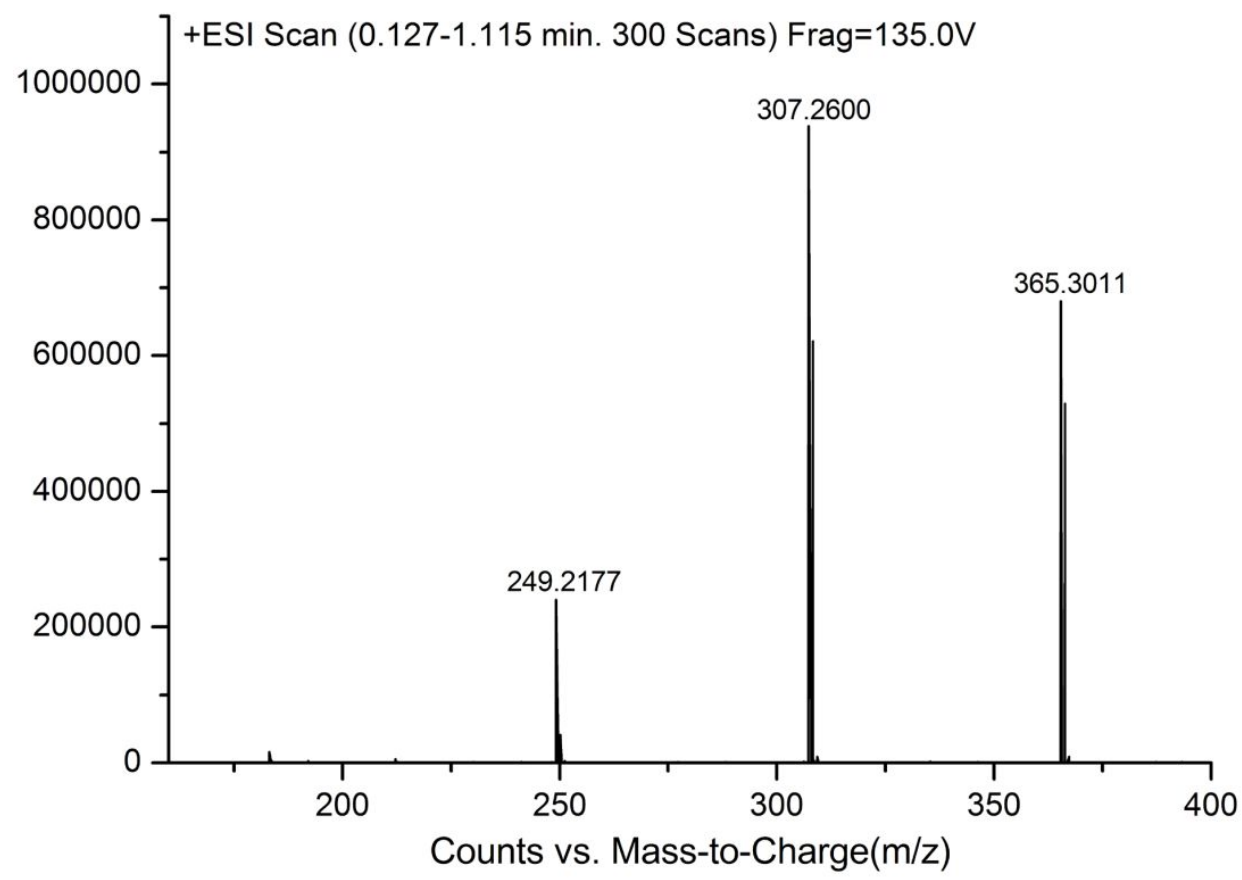

Figure S3. ESI-MS spectrum of D230 at $170{ }^{\circ} \mathrm{C}$ for $0.5 \mathrm{~h}$ under $30 \mathrm{mmHg}$ and for another $3 \mathrm{~h}$ under $3 \mathrm{mmHg}$. 




Figure S4. SEC curves of POXAU-1 and POXA.

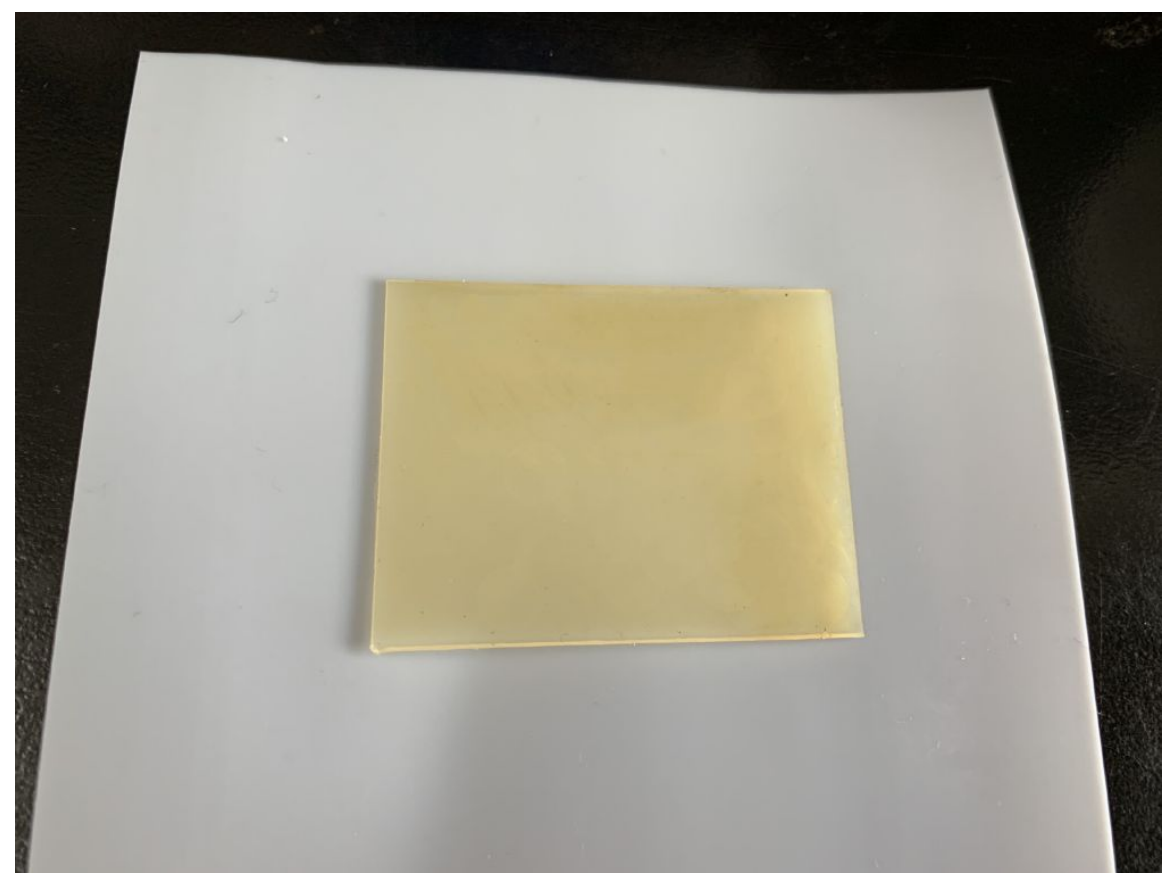

Figure S5. Photo of POXAU-1. 


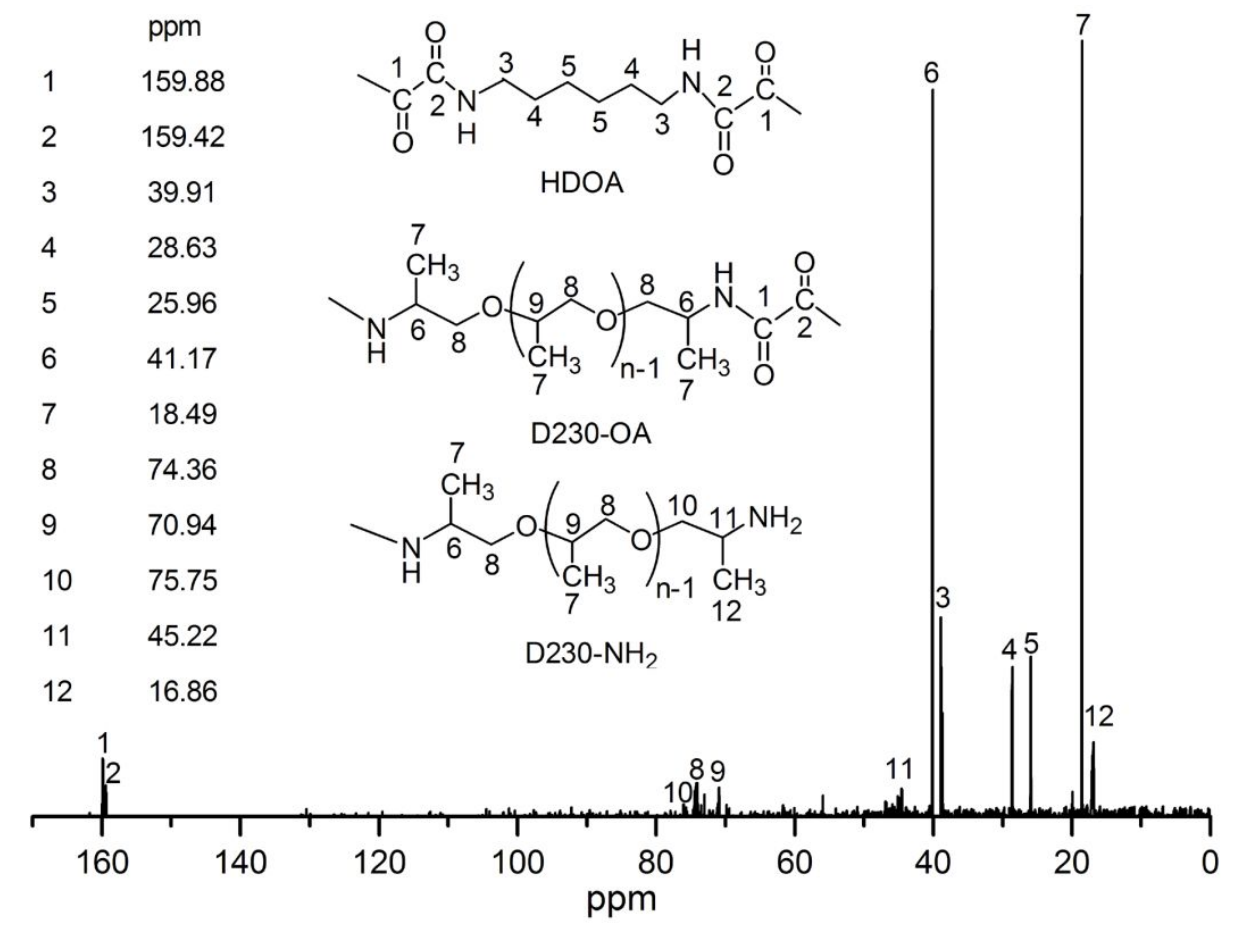

Figure S6. ${ }^{13}$ C-NMR spectrum of PrePOXA-1.

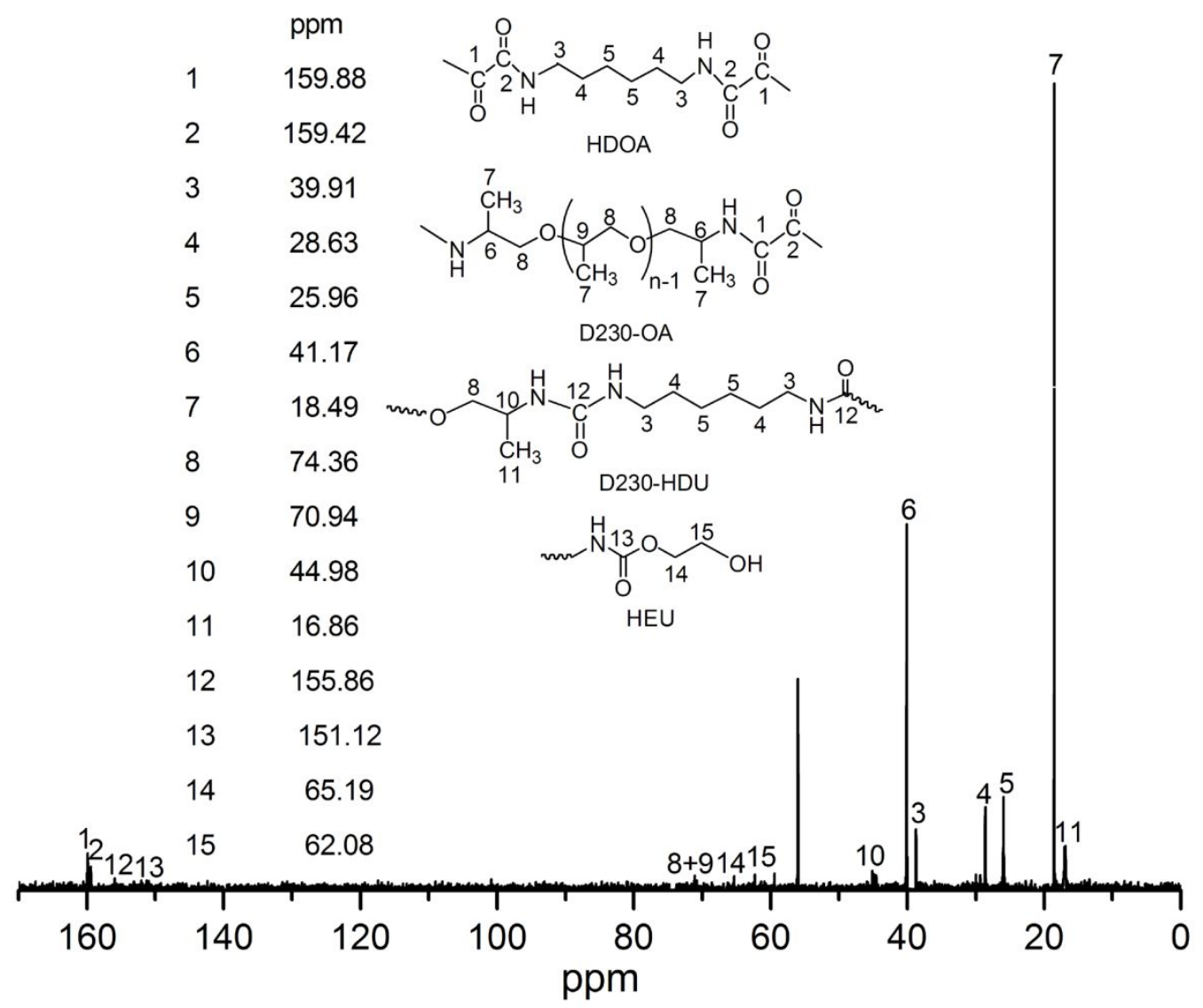

Figure S7. ${ }^{13} \mathrm{C}-\mathrm{NMR}$ spectrum of POXAU-1. 


\section{REFERENCE:}

(1) Li, S. Q.; Zhao, J. B.; Zhang, Z. Y.; Zhang, J. Y.; Yang, W. T. Aliphatic thermoplastic polyurethane-ureas and polyureas synthesized through a non-isocyanate route. $R S C A d v$. 2015, 5, 6843-6852. 